\title{
Planar Monopole UWB Antenna for Microwave Medical Image System
}

\author{
$1^{\text {st }}$ Adel Y.I. Ashyap ${ }^{1}, 2^{\text {nd }}$ Z. Z. Abidin ${ }^{2}, 3^{\text {rd }}$ S. H. Dahlan ${ }^{3}, 4^{\text {th }}$ H. A. Majid ${ }^{4}, 5^{\text {th }}$ N. \\ A.M.Alduais ${ }^{5}, 6^{\text {th }}$ S. Alamri ${ }^{6}, 7^{\text {th }}$ Raed A. Abd-Alhameed ${ }^{7}$ \\ \{ ashyap2007@gmail.com ${ }^{1}$, zuhairia@uthm.edu.my² samsulh@uthm.edu.my ${ }^{3}$ \} \\ Center for Applied Electromagnetic (EMCenter), Universiti Tun Hussein Onn Malaysia, Batu Pahat \\ 86400, Malaysia ${ }^{1,3,4}$, \\ Research Center of Wireless and Radio Science (WARAS), Faculty of Electrical and Electronic \\ Engineering, Universiti Tun Hussein Onn Malaysia, Batu Pahat 86400, Malaysia², \\ Faculty of Computer Science and Information Technology (FSKTM), Universiti Tun Hussein Onn \\ Malaysia, (UTHM) Batu Pahat 86400, Malaysia ${ }^{5}$, \\ Faculty of Engineering, Al Baha University, Al Baha, KSA \\ Faculty of Engineering and Informatics, University of Bradford, Bradford, BD7 1DP, UK ${ }^{7}$
}

\begin{abstract}
A planar monopole UWB antenna for microwave medical imaging systems is presented, and its operating frequency range from $3.09 \mathrm{GHz}$ to $10.65 \mathrm{GHz}$. The overall size of the design is $30 \times 20 \times 1.6 \mathrm{~mm}^{3}$. Two phantom models were developed to represent the arm and breast models to evaluate the design performance in terms of reflection coefficient, SAR, directivity and efficiency. The results showed that even with the phantom models, UWB bandwidth is still maintained. The directivity and efficiency of the design with and without the phantom models were studied, and its good performance was proved. The specific absorption rate (SAR) was also investigated, and it showed a value far below the safety limit. Therefore, the planar monopole UWB antenna is very suitable for microwave medical imaging systems.
\end{abstract}

Keywords: UWB, microwave medical imaging systems, SAR, microwave imaging.

\section{Introduction}

Microwave imaging systems are a method that employs an electromagnetic signal to penetrate the internal structure of tissues. It identifies and locates cancer tumours based on the high dielectric properties in contrast to normal tissues. Microwave imaging systems have several appealing features in medical applications, such as low interference, robustness to multipath fading, low cost, low complexity, precision, low power density, high-speed data rate; therefore, it has aroused a lot of research interest in the field. The current medical equipment's ability to detect tumours is not enough to meet the needs of society. The need to create a new and more reliable inspection system becomes essential. According to reports in the literature, cancer tissues exhibit different dielectric properties than normal tissues at microwave frequencies [1].

Since the researchers began using microwaves for medical purposes, the quest for an appropriate antenna has attracted a great deal of interest. Ultra-Wide Band antennas (UWB) are usually required in microwave imaging systems, especially for those who work in radar principles. It has extensive applications in high-speed and short-range wireless systems, including but not limited to personal entertainment systems, smartphones, personal health care 
systems, breast cancer detection, ground penetrating radars, identification system, medical imaging system, and military[2].

UWB planar antenna for a variety of applications has been developed. Planar antennas play a significant role among several other kinds of antennas because of their many features, such as easy incorporation with another device, high flexibility, ease of design, and small size. In the past few years, several academisation around the world have developed planar antennas to obtain wide bandwidth. Among all the introduced antenna structures, monopole UWB antennas are very common. The monopole UWB antenna has a simple structure, a low profile, a large bandwidth, and a high radiation efficiency. These types of antennas are easy to work in imaging systems. Therefore, a monopole UWB-based microwave imaging system that uses microwave radiation of a spectrum in the range of 3.1 to $10.6 \mathrm{GHz}$ is becoming one of the most feasible technologies for detecting human cancer cells [1-3].

Various designs of UWB antennas had been proposed to use microwave imaging systems to image breast tissue [4-15], such as microstrip patch antenna for the ultra-wideband (UWB) [4-6], UWB MIMO [7], circular modified UWB [8], tapered slot Vivaldi UWB[9], Conformal Polymeric wideband antenna [10], Egg-shaped UWB [11], Ultra-Wideband Microwave Antenna [12],[13], wideband magneto-electric dipole antenna [14], EBG ultra-wideband (UWB) [15]. The above-listed design [4-15] was also utilized for different microwave imaging systems, but their bandwidth, SAR, efficiency, and directivity do not reach the predicted standard.

In this paper, a very simple planar monopole UWB antenna is presented in the range of 3.09 $\mathrm{GHz}-10.65 \mathrm{GHz}$. The design was investigated on two types of human model tissues that mimic the arm and breast. CST Microwave Studio was used to design and optimized the monopole UWB antenna.

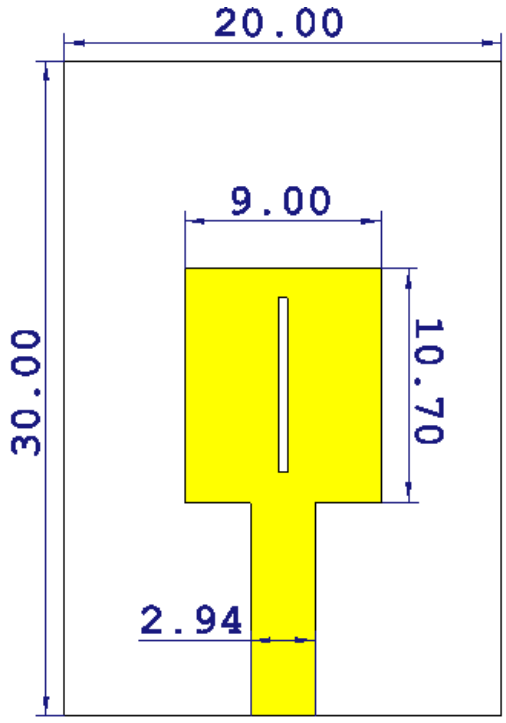

(a)

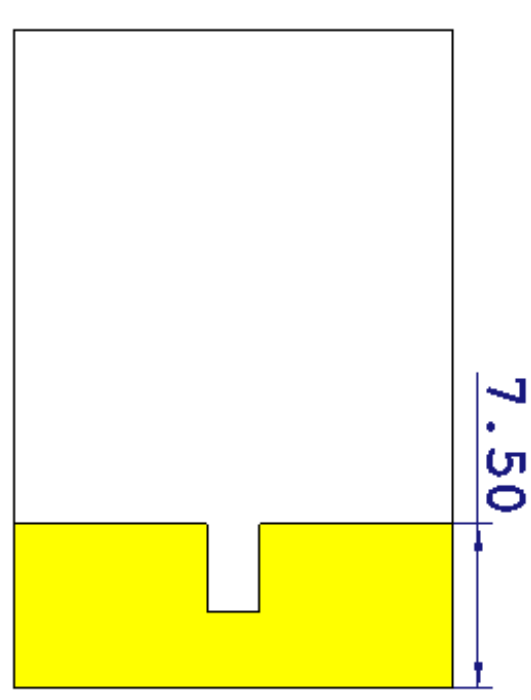

(b)

Fig. 1. Configuration of the planar monopole UWB antenna(a) Front view, and (b) Back view. 


\section{Planar Monopole UWB Antenna Design}

Figure.1 illustrates the structure of the planar monopole UWB antenna. The antenna was designed on an FR-4 substrate with a dielectric constant of 4.4, a thickness of $1.6 \mathrm{~mm}$, and a loss tangent of 0.025 . The radiating elements are made of copper with a thickness of 0.035 . The antenna is fed by a 50-ohm microstrip-fed line with a width of $2.94 \mathrm{~mm}$. The design initially started with a conventional microstrip patch shape then optimized to achieve the desired band covering $3.09 \mathrm{GHz}$ to $10.65 \mathrm{GHz}$. Three steps were taken to achieve the UWB range. The first step is to modify the ground from full to partial. The second step introduces a rectangular slot on the patch with a length of $8 \mathrm{~mm}$ and a width of $0.4 \mathrm{~mm}$ as seen in Figure 1(a). Lastly, the third step introduces a slot on the ground with a length of $4 \mathrm{~mm}$ and a width of $2.4 \mathrm{~mm}$ as seen in Figure 1(b). The final antenna has an overall dimension of $30 \times 20 \times 1.6 \mathrm{~mm}^{3}$.

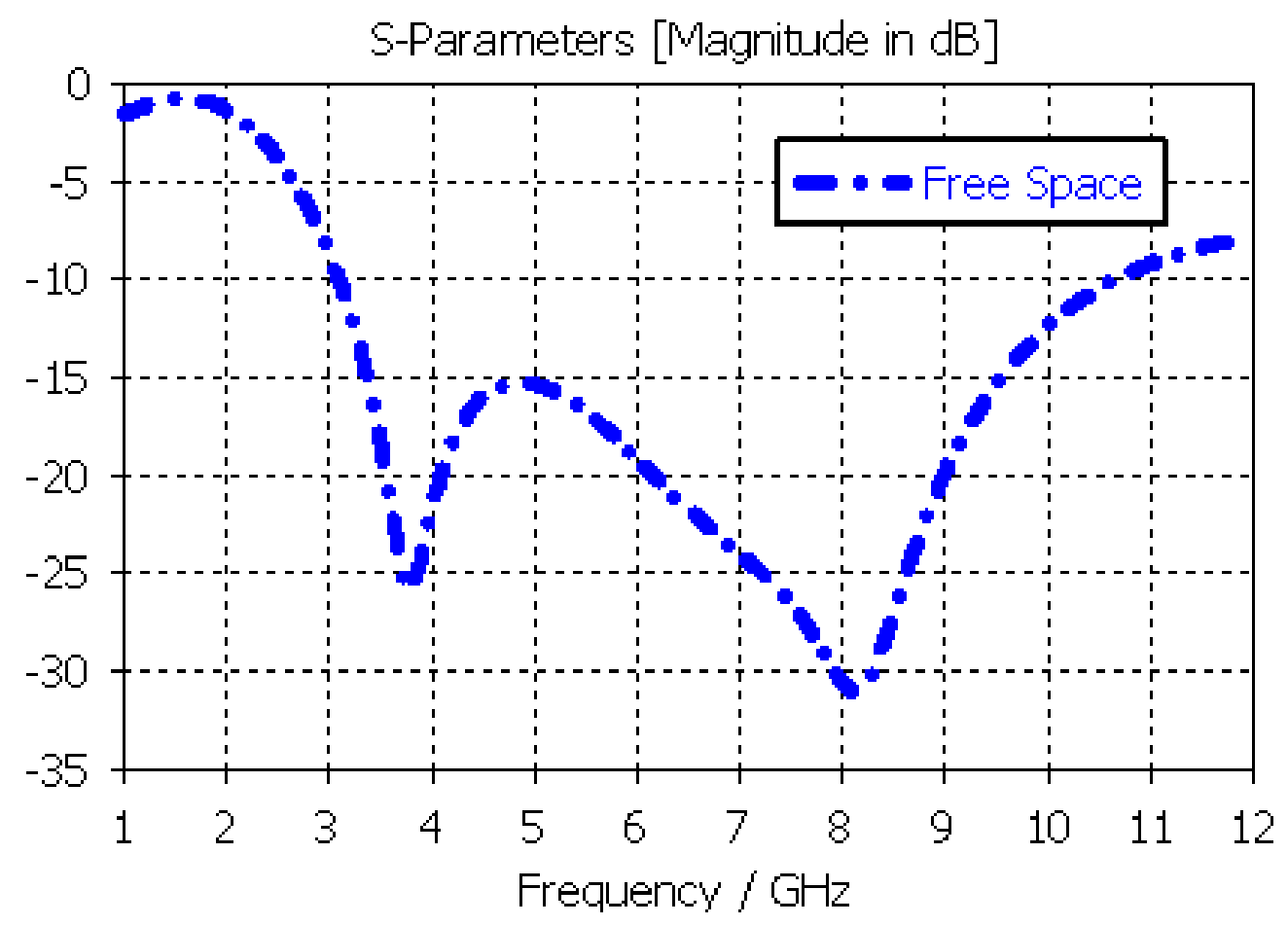

Fig. 2. Reflection coefficient of the planar monopole UWB antenna.

The reflection coefficient of the presented planar monopole UWB antenna is depicted in Figure 2. The result shows that the antenna operates from $3.09 \mathrm{GHz}$ to $3.65 \mathrm{GHz}$, which is suitable for microwave imaging systems applications. The antenna demonstrates minimum directivity of $3.03 \mathrm{dBi}$ at a lower frequency $(3.5 \mathrm{GHz})$ and a maximum directivity of $4 \mathrm{dBi}$ at a higher frequency $(9.5 \mathrm{GHz})$. The presented design has an efficiency of $69.9 \%$ at a lower frequency $(3.5 \mathrm{GHz})$ and $81.4 \%$ at a higher frequency $(9.5 \mathrm{GHz})$. 


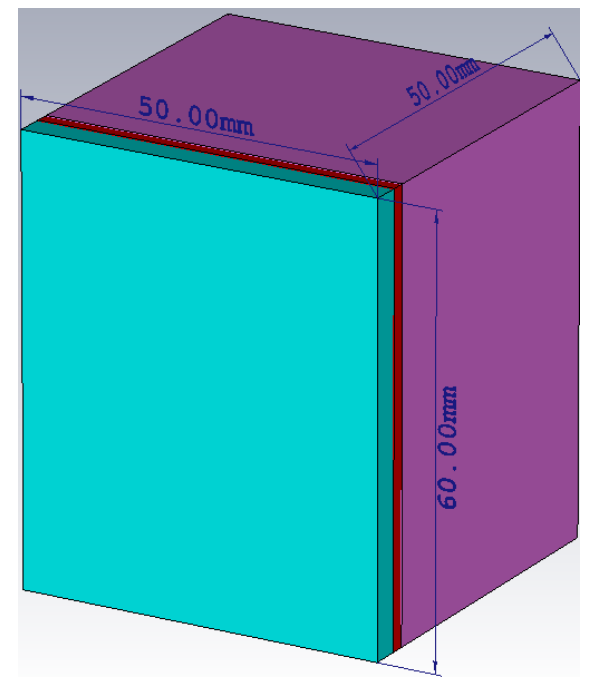

(a)

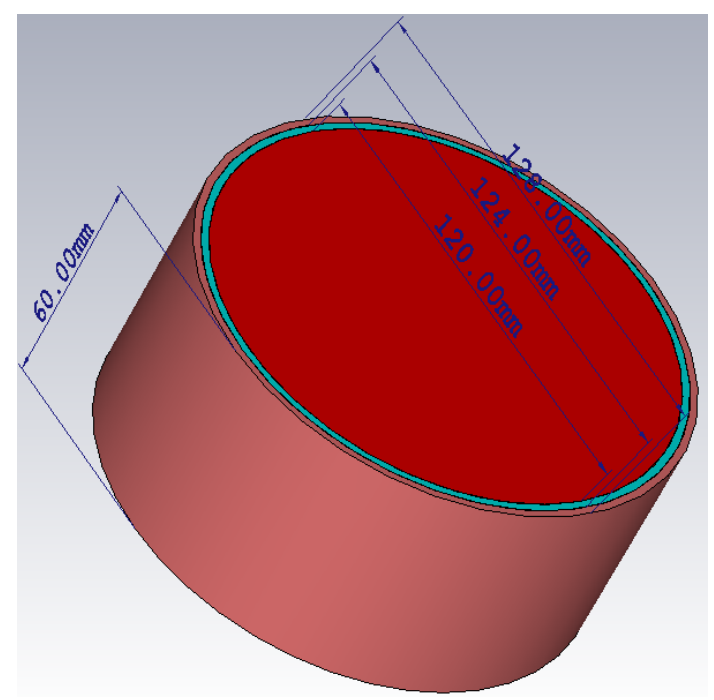

(b)

Fig. 3. Phantom models(a) Chest,and (b) Breast

\section{Performance of the UWB Antenna on Body}

To better understand the planar's monopole UWB antenna's performance near human tissues, two Phantom models were developed for this research, which consists of three layers. The first model is a rectangular shape imitating an arm model, and the second model is a cylindrical shape imitating a breast tissue model. The arm model consists of muscle $(\sigma=1.74$, thickness $=34, \varepsilon r=52.73)$, fat $(\sigma=0.1$, thickness $=2, \varepsilon r=5.28)$, and skin $(\sigma=1.59$, thickness $=4, \varepsilon r=45.85)$. These values are evaluated at $3.1 \mathrm{GHz}[16]$. The breast model uses the same layers as the arm model, except the muscle layer was changed with a plastic cover with permittivity of 1.7 .

As illustrated in Figure 3(a), the dimension of the rectangular arm is $60 \times 50 \times 50 \mathrm{~mm}^{3}$, whereas Figure 3(b) depicts the breast tissue model with a diameter of $128 \mathrm{~mm}$ and length 60 $\mathrm{mm}$. Figure 4 shows the planar monopole UWB antenna's reflection coefficient placed in free space, on the arm model, and the breast model. The result shows that the desired UWB band is achieved from $3.1 \mathrm{GHz}$ to $10.6 \mathrm{GHz}$ in all cases.

The planar monopole UWB antenna's performance in terms of directivity and efficiency while operating on the arm and breast model was carried out. The results are presented in Table 1. It is realized that when the design is placed on the phantom models, the directivity is increased compared to the case of free space. This is due to the interaction between the antenna ground plane and the phantom models as the phantom models act as an additional dielectric that directs the front's directivity. It also realized that the efficiency drop compared to free space. This is due to the high conductivity of phantom models. 
Table 1. Directivity and efficiency of planar monopole UWB antenna on arm, breast, and free space at $3.5 \mathrm{GHz}$ and $9.5 \mathrm{GHz}$.

\begin{tabular}{lcccc}
\hline Phantom Models & \multicolumn{2}{c}{ Directivity $(\mathrm{dBi})$} & \multicolumn{2}{c}{ Efficiency $(\%)$} \\
\cline { 2 - 5 } & $3.5(\mathrm{GHz})$ & $9.5(\mathrm{GHz})$ & $3.5(\mathrm{GHz})$ & $9.5(\mathrm{GHz})$ \\
\cline { 2 - 5 } Arm Model & 6.32 & 9.87 & 57.7 & 73.3 \\
Breast Model & 5.91 & 7.07 & 58.25 & 70.1 \\
Free space & 3.03 & 4 & 69.9 & 81.4 \\
\hline
\end{tabular}

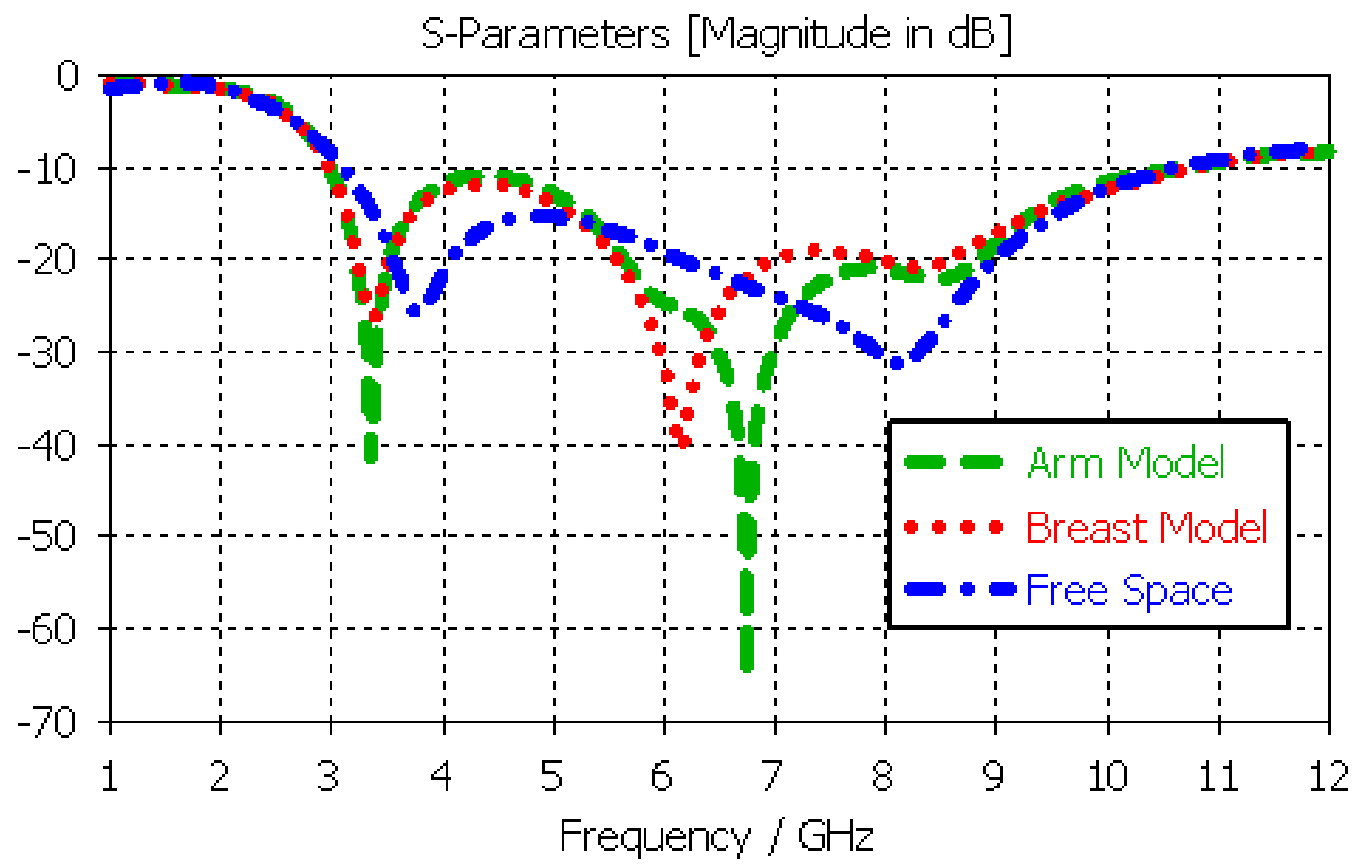

Fig. 4. Reflection coefficient of the planer monopole UWB antenna on arm, breast models.

The specific absorption rate (SAR) of the planar monopole UWB antenna over a human body was carried out to find the total power that the planar monopole UWB antenna can transmit within the safety restrictions. The assessment is conducted in accordance with the standards established by FCC. The safety limit should not be greater than $1.6 \mathrm{~W} / \mathrm{kg}$ over $1 \mathrm{~g}$ of tissue. The SAR values were taken at $3.5 \mathrm{GHz}$ and $9.5 \mathrm{GHz}$ based on IEEE C95.1 with an input power of $100 \mathrm{~mW}$ [17-20]. The results are depicted in Figure 5 and Figure 6. The SAR values of the arm and breast models were $0.369 \mathrm{w} / \mathrm{kg}$ and $0.254 \mathrm{w} / \mathrm{kg}$ at $3.5 \mathrm{GHz}$, and $0.4 \mathrm{w} / \mathrm{kg}$ and 0.364 $\mathrm{w} / \mathrm{kg}$ at $9.5 \mathrm{GHz}$, respectively. It is revealed that the design meets the standard with values far below the safety limits, which will not affect the body. 


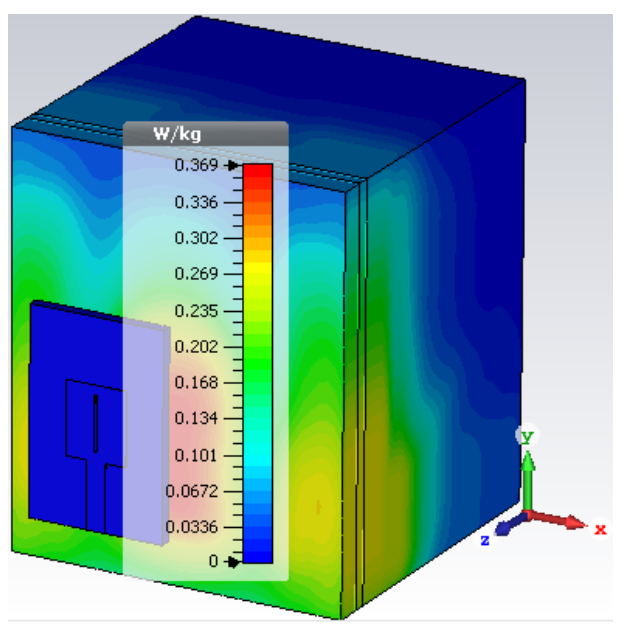

(a)

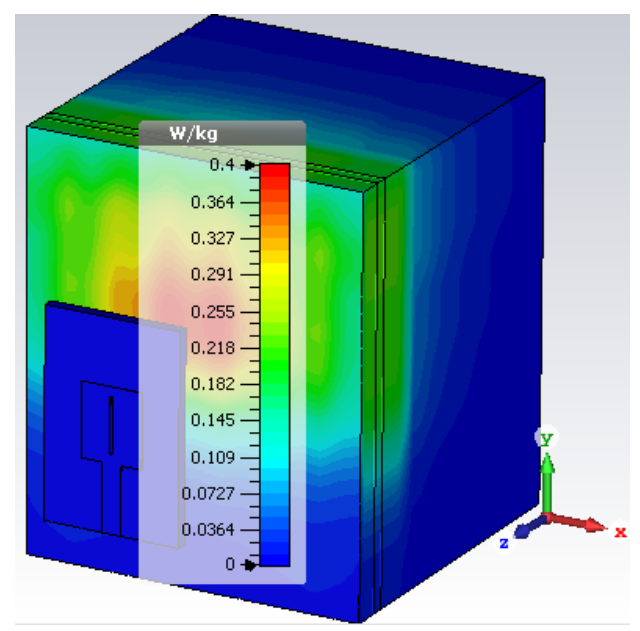

(b)

Fig. 5. 3D SAR results of the planar monopole UWB antenna on the arm at frequencies of (a) $3.5 \mathrm{GHz}$ and (b) $9.5 \mathrm{GHz}$.

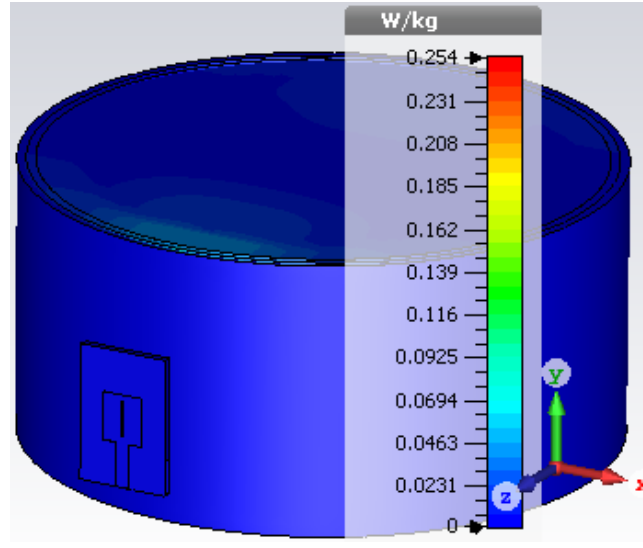

(a)

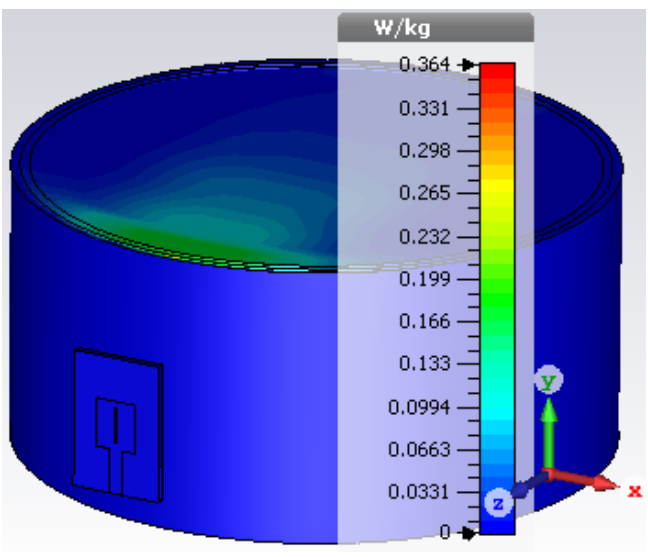

(b)

Fig. 6. 3D SAR results of the planar monopole UWB antenna on the breast at frequencies of (a) $3.5 \mathrm{GHz}$ and (b) $9.5 \mathrm{GHz}$.

\section{Conclusion}

A planar monopole UWB antenna for microwave medical imaging systems is introduced. The operating frequency covers the UWB bandwidth from $3.09 \mathrm{GHz}$ to $10.65 \mathrm{GHz}$ with an overall dimension of $30 \times 20 \times 1.6 \mathrm{~mm}^{2}$. Two phantom models were developed, a rectangular 
shape mimics the arm, and a cylindrical shape mimics the breast. The design revealed a good reflection coefficient with and without the presence of the phantom models covering the UWB bandwidth from $3.09 \mathrm{GHz}$ to $10.65 \mathrm{GHz}$. The design also shows a directivity of $4 \mathrm{dBi}$ (free space), 9.87dBi (arm model), and $7.07 \mathrm{dBi}$ (breast mode), while an efficiency of $81.4 \%$, (free space), $73.3 \%$ (arm model), and $70.1 \%$ (breast mode) at a frequency of $9.5 \mathrm{GHz}$. The SAR was investigated based on the arm and breast models, and the results demonstrated that the SAR values were $0.4 \mathrm{w} / \mathrm{kg}$ and $0.364 \mathrm{w} / \mathrm{kg}$, respectively, at a frequency of $9.5 \mathrm{GHz}$.

\section{References}

[1] Mahmud, M. Z., Islam, M. T. \& Samsuzzaman, M. A high performance UWB antenna design for microwave imaging system. Microw. Opt. Technol. Lett. 58, 1824-1831 (2016).

[2] Mahmud, M., Islam, M., Misran, N., Almutairi, A. \& Cho, M. Ultra-Wideband (UWB) Antenna Sensor Based Microwave Breast Imaging: A Review. Sensors 18, 2951 (2018).

[3] Seman, F. C. et al. performance evaluation of a star-shaped patch antenna on polyimide film under various bending conditions. prog. electromagn. Res. Lett. 85, 125-130 (2019).

[4] Hammouch, N. \& Ammor, H. A confocal microwave imaging implementation for breast cancer detection. Indones. J. Electr. Eng. Informatics 7, 263-270 (2019).

[5] Sheela, J. J. J. et al. Novel Directional Antennas for Microwave Breast Imaging Applications. in 2020 International Conference on Smart Electronics and Communication (ICOSEC) 00, 599-603 (IEEE, 2020).

[6] Karli, R., Ammor, H. \& El Aoufi, J. Miniaturized UWB microstrip antenna for microwave imaging. WSEAS Trans. Inf. Sci. Appl. 11, 122-129 (2014).

[7] Ziani, D., Meriah, S. M. \& Merad, L. UWB MIMO array design for medical applications. in 2016 International Conference on Electrical Sciences and Technologies in Maghreb (CISTEM) 1-3 (IEEE, 2016).

[8] Widyatama, P. Z., Nugroho, B. S. \& Nur, L. O. Design of Circular Modified UWB Antenna Microstrip for Brain Cancer Detection. in 2019 IEEE Asia Pacific Conference on Wireless and Mobile (APWiMob) 33-36 (IEEE, 2019). doi:10.1109/APWiMob48441.2019.8964123

[9] Akazzim, Y., Kanjaa, M., Mrabet, O. EL, Jofre, L. \& Essaaidi, M. An UWB Tapered Slot Vivaldi Antenna (TSA) with Improved Characterestics. in 2019 IEEE 19th Mediterranean Microwave Symposium (MMS) 2019-Octob, 1-4 (IEEE, 2019).

[10] Limbah, M. H., Lago, H., Soh, P. J. \& Teo, K. T. K. Wideband Conformal Polymeric Based Antenna for Microwave Medical Imaging System. in 2020 IEEE 2nd International Conference on Artificial Intelligence in Engineering and Technology (IICAIET) 1-4 (IEEE, 2020).

[11] Cherian, P., Anjit, T. A. \& Mythili, P. A compact egg-shaped UWB antenna for breast dielectric profile imaging. Int. J. Sci. Technol. Res. 9, 4672-4681 (2020).

[12] Aminudin Jamlos, M. et al. High Gain of Directional Ultra-Wideband Array Antenna Using Flat Reflector Structure for Microwave Imaging. IOP Conf. Ser. Mater. Sci. Eng. 557, 012018 (2019).

[13] Ahmed, S. S., Mahdi, J. F. \& Kadhim, M. A. Design of Ultra-Wideband Microwave Antenna Array for Detection Breast Cancer Tumours. IOP Conf. Ser. Mater. Sci. Eng. 881, 012112 (2020).

[14] Chen, L. et al. Design of a UWB Antenna for Microwave Imaging. ISAP 2018 - 2018 Int. Symp. Antennas Propag. 825-826 (2019).

[15] Shanwar, A. R. \& Othman, N. S. UWB printed antenna for medical applications. in TENCON 2017 2017 IEEE Region 10 Conference 2017-Decem, 2931-2936 (IEEE, 2017).

[16] Danjuma, I. M., Akinsolu, M. O., See, C. H., Abd-Alhameed, R. A. \& Liu, B. Design and Optimization of a Slotted Monopole Antenna for Ultra-Wide Band Body Centric Imaging Applications. IEEE J. Electromagn. RF Microwaves Med. Biol. 4, 140-147 (2020).

[17] Ashyap, A. Y. I. et al. Robust and efficient integrated antenna with EBG-DGS enabled wide bandwidth for wearable medical device applications. IEEE Access 8, 56346-56358 (2020). 
[18] Ashyap, A. Y. I., Abidin, Z. Z., Dahlan, S. H., Majid, H. A. \& Seman, F. C. A compact wearable antenna using EBG for smart-watch applications. Asia-Pacific Microw. Conf. Proceedings, APMC 2018-November, 1477-1479 (2019).

[19] I. Ashyap, A. Y. et al. A wearable antenna based on fabric materials with circular polarization for Body-centric wireless communications. Indones. J. Electr. Eng. Comput. Sci. 18, 335 (2020).

[20] Ashyap, A. Y. I. et al. An Overview of Electromagnetic Band-Gap Integrated Wearable Antennas. IEEE Access 8, 7641-7658 (2020). 